\title{
Обговорення результатів
}

В настановах [3, 4] спеціалісти фірми Siemens дають рекомендації по визначенню параметрів об’єкта керування зі статичними властивостями за результатами активного експерименту та на їх основі приводять залежності по визначенню параметрів регулятора. Однак там нема вказівок, як обирати налаштування регулятору в системі з ОК, у якого астатичні властивості і в моделі якого є інтегратор. Це змушує звертатись до інших літературних джерел, наприклад [5].

3 певною обережністю слід застосовувати функцію самоналаштування, яка вбудована в алгоритм FB PID_Compact.

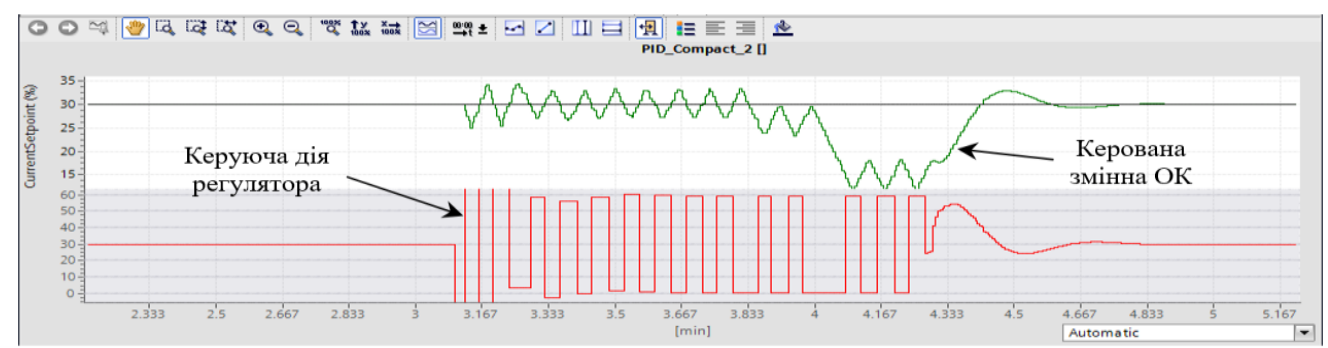

Рис. 7 - Приклад дії функції самоналаштування FB PID_Compact

Як видно з рисунку 7, ця функція передбачає активні пошукові зміни керуючої дії регулятора, що приводить до значних коливань керованої змінної ОК, а це допустимо далеко не для всіх технологічних процесів.

Автори цілком свідомі того, що матеріал статті не містить наукової новизни, але сподіваються, що вона принесе практичну користь спеціалістам, які використовують функціональні блоки ПІД-регулювання для контролерів Simatic S7-1200/S7-1500.

\section{Висновки}

Запропоновані зміни коду функціональних блоків бібліотеки “LSim”, які реалізують ланку запізнення, інерційну ланку першого порядку, інтегруючу ланку, дозволяють врахувати довільні початкові умови в цих ланках, що забезпечує моделювання динамічно сталих режимів САР в середовищі Step 7 TIA Portal.

\section{Список використаних джерел}

[1] Library for Controlled System Simulation with STEP7 (TIA Portal). ID: 79047707, V3.0.0. Siemens AG, 03/2017. 46 p.

[2] Modular PID Control (Модульное ПИД-управление). Руководство пользователя. C79000-G7076-C121-01. Siemens AG, 1997. $258 \mathrm{c}$

[3] S7-1200, S7-1500 PID control Function Manual. A5E35300227-AC. Siemens AG, 12/2017. 551 p.

[4] Closed-Loop Control with "PID_Compact" V2.2. Entry-ID: 79047707. Siemens AG, 03/2017. 43 p.

[5] Наладка средств автоматизации и автоматических систем регулирования. Справочное пособие. Под ред. А.С. Клюева. М.: Энергоатомиздат, 1989. 368 с.

\section{References}

[1] Library for Controlled System Simulation with STEP7 (TIA Portal). ID: 79047707, V3.0.0. Siemens AG, 03/2017. 46 p.

[2] Modular PID Control. Rukovodstvo polzovatelya. C79000-G7076-C121-01. Siemens AG, 1997. 258 p.

[3] S7-1200, S7-1500 PID control Function Manual. A5E35300227-AC. Siemens AG, 12/2017. 551 p.

[4] Closed-Loop Control with "PID_Compact" V2.2. Entry-ID: 79047707. Siemens AG, 03/2017. 43 p.

[5] "Naladka sredstv avtomatizatsii i avtomaticheskih sistem regulirovaniya. Spravochnoe posobie,". A.S. Klyueva Ed. Moscow, Energoatomizdat, 1989. 368 p.

\section{АНАЛІЗ ОСНОВНИХ ПЕРЕВАГ ТА НЕДОЛІКІВ РІЗНОМАНІТНИХ ФРЕЙМВОРКІВ АВТОМАТИЗАЦӤ ТЕСТУВАННЯ}

\author{
Антонова А. ${ }^{1}$, Помогаєв Д. ${ }^{2}$ \\ Одеська національна академія харчових технологій, м. Одеса, Україна \\ ORCID: ${ }^{1}$ http://orcid.org/0000-0003-3599-0983, ${ }^{2}$ http://orcid.org/0000-0002-6212-4848 \\ E-mail: ${ }^{1}$ allaantonova62@gmail.com, ${ }^{2}$ dimonpom@gmail.com
}

Copyright (C) 2020 by author and the journal "Automation of technological and business-processes". This work is licensed under the Creative Commons Attribution International License (CC BY). http://creativecommons.org/licanses/by/4.0

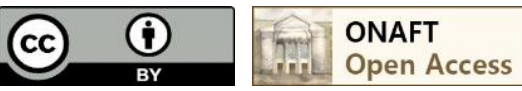

DOI: https://doi.org/10.15673/atbp.v12i4.1935 
http://www.atbp.onaft.edu.ua/

\begin{abstract}
Анотація. У статті розглядаються програмні засоби для автоматизації тестування програмних продуктів. Авторами проведено аналіз впливу фреймворків автоматизачії тестування на сферу розробки програмного забезпечення, також проаналізовано низку задач тестувальників, які можна вирішити за допомогою цих засобів. Сфера IT проникає в усі аспекти життя людини уже давно, але тільки в останні декілька років спостерігається небувала тенденція стрімкого зростання кількості програм, сайтів, спеціалізованих програмних продуктів тощо. Цей стрімкий ріст обумовлений насамперед необхідністю спрощувати виконання рутинних трудомістких задач у багатьох сферах життєдіяльності, щу донедавна виконували люди. Вже зараз різноманітне програмне забезпечення застосовуються майже у всіх сферах життя $і$ згодом повністю охопить усі не творчі напрями діяльності людини. Широке застосування комп'ютерних технологій призвело не тільки до збільшення чисельності програмного забезпечення, але й до стрімкого зростання вимог до иџих програмних продуктів. Від їх коректного виконання, часом, залежить не тільки користувач, але й иілі галузі комериійного і державного правління. Тестування - один $з$ найважливіших етапів контролю якості в прочесі розробки програмного забезпечення. Автоматизоване тестування $\epsilon$ його складовою частиною. Воно використовує програмні засоби для створення, виконання тестів $і$ перевірки результатів їх виконання. Автоматизаџія тестування допомагає оптимізувати час на проведення тестування: надає тестувальникам можливість швидко і якісно проводити тести, мати можливість легко їх міняти, щзо спрощує сам процес тестування. Авторами проведено дослідження і порівняльний аналіз традиційної методології тестування та Agile методологї та зроблені висновки о їх перевагах і недоліках. Основна мета изього дослідження це проаналізувати процеси автоматизації тестування програмних продуктів, визначити основні переваги та недоліки різноманітних фреймворків автоматизаџії тестування, зробити виводи щзодо доречності використання того чи іншого рімення та засобу.
\end{abstract}

Abstract. The article discusses software tools for automating testing of software products. The authors analyzed the impact of test automation frameworks on the field of software development, and also analyzed a number of tasks for testers that can be solved using these tools. The IT sphere has been penetrating all aspects of human life for a long time, but only in the last few years has there been an unprecedented trend of a rapid growth in the number of programs, websites, specialized software products, and the like. This rapid growth is primarily due to the need to simplify the performance of routine labor-intensive tasks in many spheres of life, until recently people performed. Already now, a variety of software is used in almost all spheres of life and subsequently will fully cover all non-creative areas of human activity. The widespread use of computer technology has led not only to an increase in the number of software, but also to a rapid growth in requirements for these software products. Their correct implementation, time, depends not only on the user, but also on entire branches of commercial and state government. Testing is one of the most important stages of quality control in the software development process. Automated testing is an integral part of it. It uses software to create, run tests, and check the results of their execution. Test automation helps to optimize testing time: it provides testers with the ability to quickly and efficiently conduct tests, to be able to easily change them, which simplifies the testing process itself. The authors conducted a study and comparative analysis of the traditional testing methodology and Agile methodology and made conclusions about their advantages and disadvantages. The main goal of this study is to analyze the processes of automation of testing software products, to determine the main advantages and disadvantages of various test automation frameworks, to draw conclusions regarding the appropriateness of using one or another solution and tool.

Ключові слова: автоматизація тестування, фраймворк, тестування програмного забезпечення

Keywords: test automation, framework, quality assurance

\title{
Вступ
}

Стрімке розповсюдження інформаційних технологій у всі сфери життєдіяльності людини спровокувало й потребу в збільшені кількості спеціалізованих програм, що в тому чи іншому вигляді допомагали людині. Такий ріст обумовлений насамперед необхідністю спрощувати виконання рутинних трудомістких задач у багатьох сферах життєдіяльності, що донедавна виконували люди. Активне використання переваг інформаційних технологій не тільки дасть можливість людям займатися більш творчими та цікавими задачами, але й мінімізує кількість помилок та неточностей, що спричиняв людський фактор. Вже зараз різноманітне програмне забезпечення застосовуються майже у всіх сферах життя і згодом повністю охопить усі не творчі напрями діяльності людини.

\section{Аналіз етапів розробки програмного продукту}

Будь-яке впровадження спеціалізованого програмного забезпечення має на увазі той факт, що перед безпосередньо використанням програмного продукту був етап його створення.

Говард Бетьєр (молодший) описує процес створення програмного забезпечення наступним чином:

Процес розробки - це процес діалогу, в рамках якого знання, які необхідно перетворити на програмне забезпечення, набуваються та реалізуються. Це ітераційний процес, в якому розробляємий продукт сам діє як засіб спілкування, завдяки якому учасники можуть отримати більше корисних знань [1]. 
Після майже півстоліття розробки програмного забезпечення досвід минулих проектів узагальнюється в найкращі практики 3 виробництва високоякісного програмного забезпечення. Встановлено, що розробка програмного забезпечення зазвичай включає такі етапи:

- аналіз попиту та вимог;

- проектування системи;

- програмування;

- тестування і налагодження;

- експлуатація, супровід і підтримка.

Згадуючи про процес розробки програмного забезпечення, неможливо ігнорувати роль тестування в ньому. Тестування програмного забезпечення можна трактувати як процес перетворення латентних дефектів на ідентифіковані. Цей вирішальний етап життєвого циклу розробки програмного забезпечення виявляє приховані дефекти розроблюваного продукту.

Дуже цікава методологія Agile Testing (Agile тестування) — це тестування програмного забезпечення із дотриманням принципів гнучкої розробки програмного забезпечення. Тестування проводиться паралельно 3 розробкою. Команда тестувальників працює постійно у ритмі зміни вимог, отримує часті релізи і слідкує за змінами коду команди розробників під час тестування програми.

Слід розуміти, що у Agile методології тестування не є окремим етапом розробки, як у традиційних моделях розробки програмних засобів. Часовий відрізок підготовки до тестування суттєво менший у Agile порівняно 3 традиційними моделями. Команда тестування під час Agile починає працювати 3 початкових етапів опрацювання вимог і малих частинок функціональностей, тоді як в традиційних моделях команда тестування працює на повну програму вже після розробки якогось завершеного модуля або цілої програми.

\section{Роль тестування в процесі розробки програмного забезпечення}

Абсолютно всі проекти потребують тестування, так як без тестів неможливо визначити наявність в продукті критичних помилок, його відповідність вимогам, рівень забезпечення безпеки і т. д. Тестування програмних продуктів використовує приблизно 40-50 відсотків усіх ресурсів і становить 50-60 відсотків від загальної вартості проекту [2]. Етап тестування, який вважається одним з основних випробувань на шляху розробки програмного забезпечення, можна розглядати як гарну можливість поліпшити якість, оптимізувати витрати і скоротити час виходу продукту на ринок програмного забезпечення. Така оптимізація є дуже бажаною у сучасних реаліях ринку, коли галузь програмного забезпечення стикається з жорсткою конкуренцією, та компанії намагаються водночас скоротити бюджет та строки проектів [3].

Як і раніше, ручне тестування є важливою частиною процесу перевірки програмного продукту на різних стадіях розробки. Під час виконання такого тестування людина - тестувальник користується розроблюваною програмою та проводить над нею різноманітні тести, які інтерпретують та аналізують поведінку продукту за різних вхідних умов [4]. Пізніше тестувальник готує звіти та надає коментарі щодо стану якості продукту, порівнюючи фактичні результати з очікуваними.

Загалом ручне тестування - це монотонний і трудомісткий процес, що вимагає великих затрат часу. Крім цього, в процесі ручного тестування наявний «людський фактор», отже частина помилок може залишитися невиявленою, а деякі результати перевірки можуть виявитися суб'єктивними [5].

3 іншого боку, автоматичне тестування зводиться до використання деяких стандартних програмних рішень для контролю виконання тестів на тестовому програмному забезпеченні. Цей процес також передбачає встановлення передумов, узгодження фактичних результатів із прогнозованими, а також подальше документування спостережень згідно зі стандартизованими протоколами. Процеси, що виконує людина, автоматизуються і виконуються програмою або технікою. Такий підхід допомагає у досягненні важливої мети у розробці програмного забезпечення - збільшення продуктивності, зменшення часу виконання задачі і підвищення якості продукту.

\section{Переваги автоматизації тестування}

До основних переваг автоматизації тестування можна віднести:

- підвищення швидкості тестування без втрати якості;

- підвищення якості тестування (при використанні автоматизованого тестування, «людський фактор» не впливає на якість тестування);

- можливість виконання видів тестування, що не можуть бути виконанні ручним способом, або потребують значних витрат;

- повторне використання;

- автоматичне збереження звітів про результати роботи програм.

Також автоматизація має певні недоліки:

- написані тести завжди працюють однаково, що в деяких випадках може призвести до пропуску помилки, яку б помітила людина при ручному тестуванні;

- пропуск дрібних недоліків (тести можуть пропускати дрібні помилки, на які не були запрограмовані);

- витрати на розробку і підтримку (залежать від складності й частоти оновлень продукту). 
http://www.atbp.onaft.edu.ua/

Проте незважаючи на перераховані мінуси, при правильному підході та володінні необхідними ресурсами, можливо досягти результатів, близьких до ідеалу. Загалом автоматизація тестування, завдяки підвищенню швидкості процесу тестування, є найбільш ефективним рішенням в умовах жорстких строків готовності продукту.

Як результат, сьогодні існує багато комерційних програмних засобів, що дозволяють впроваджувати автоматизацію тестування. Такі рішення широко доступні, і чисельні організації займаються наданням послуг із забезпечення якості тестування. Але слід мати на увазі, що автоматизація тестування - це процес, ціна помилки в якому дуже велика. Перед його початком слід врахувати безліч факторів, наприклад, яка функція вимагає автоматизованого тестування, а для якої створення автотестів не принесе значних переваг [5]. Автоматизація тестування вимагає великих первинних вкладень з точки зору аналізу функцій програмного забезпечення, створення сценаріїв, закупівлі інструментів, навчання тощо але при правильному підході окупає себе.

\section{Сучасні фреймворки автоматизації тестування}

Selenium - це один 3 найпопулярніших фреймворків для автоматизації тестування, який складається 3 великої кількості інструментів і плагінів. Загалом Selenium - це великий проект, в рамках якого розробляються серія програмних продуктів з відкритим кодом, серед яких слід зазначити:

- Selenium WebDriver - програмна бібліотека, що дозволяє управляти браузером;

- Selenium Grid - це кластер, що складається з декількох Selenium-серверів. Він призначений для організації розподіленої мережі, що дозволяє паралельно запускати багато браузерів на великій кількості машин;

- Selenium IDE - це плагін до браузера Firefox, який може записувати дії користувача, відтворювати їх, а також генерувати код для WebDriver, в якому виконуються ті ж самі дії;

- Selenium-рекордер.

Katalon Studio - це ефективний інструмент автоматизації процесу тестування сайтів, веб - сервісів, мобільних додатків. Katalon Studio вважають «нащадком» таких фреймворків, як Appium i Selenium. Це пов'язано 3 тим, що він перейняв у них ряд плюсів, пов'язаних з інтегрованою автоматизацією тестування програмного забезпечення. Для комфортної взаємодії з цим інструментом потрібно володіти як початковими знаннями в тестуванні, так і бути експертом своєї справи. На практиці запуск власного проекту по автоматизації тестування не викликає труднощів навіть у людей, далеких від програмування. Наприклад, це можна зробити за допомогою функції Object Spy. Що стосується програмістів і більш досвідчених тестувальників, то для них Katalon Studio стане дуже корисним інструментом в плані економії часу як при написанні нових бібліотек, так і для підтримки вже існуючих скриптів.

Unified Functional Testing (UFT, перекладається, як комплексне функціональне рішення для тестування) - це популярний комерційний інструмент для автоматизації тестування. По суті, UFT - це набір функцій, призначених для тестування веб - сервісів, сайтів, API, графічного інтерфейсу мобільних, десктопних і веб - додатків практично на всіх платформах, що існують на сьогоднішній день. Інструмент має розширений функціонал розпізнавання об'єктів на основі їх зображень. Крім того, доступні багаторазові тестові компоненти, а також документація по автоматизації. Для роботи інструменту використовується Visual Basic Scripting Edition, завдяки чому є можливість управляти об'єктами або зберігати інформацію про виконане тестування. Крім того, UFT інтегрований з Mercury Quality Center i Mercury Business Process Testing, також він підтримує CI за допомогою інтеграції з такими СІ-інструментами, як Јеnkins.

Test Complete є ефективним інструментом для виконання тестування мобільних, десктопних і веб - додатків. Він розроблений компанією SmartBear і підтримує VBScript, JavaScript, Python, C++ Script. Так само як і в випадку 3 Katalon Studio, за допомогою Test Complete тестувальники зможуть без проблем проводити керування даними тестування, а також тестування із застосуванням ключових слів. Додатково в інструменті є зручна функція запису процесу тестування з можливістю подальшого відтворення. Якщо порівнювати Test Complete 3 UTF, то вони схожі принципами розпізнавання об'єктів GUI. Це дозволяє уникнути додаткових турбот по підтримці тестових скриптів при змінах AUT. Ще інструмент може інтегруватися з Jenkins під час CI-процесу.

\section{Висновки}

Говорячи про програмні засоби автоматизації тестування, процес вибору фреймворку, що буде являти собою основу для впровадження автотестів, є дуже важливим підготовчим етапом, що може вплинути на успішність процесів тестування на проекті. Зараз існує велика кількість різноманітних інструментів, що дозволяють автоматизувати тестування. У ході аналізу та дослідження ринку програмного забезпечення для автоматизованого тестування було обрано чотири фреймворки: Selenium, Katalon Studio, Unified Functional Testing, Test Complete.

Після ретельного, всебічного аналізу систем контролю та створення автоматичного тестування було прийнято рішення в новому проекті використовувати фреймворк Selenium в якості програмного забезпечення для автоматизованого тестування, так як недоліки цього фреймворку не $є$ такими, що принципово заважають його використовуванню, а переваги, такі як величезна спільнота й відсутність обмежень для інтеграцій, є суттєвими.

\section{Список використаних джерел}

[1] Liangliang H. Development Trend of Software Process Model / H. Liangliang, Z. Jinsheng, M. Xiaoyu. // IOP Conference Series: Materials Science and Engineering. - 2019. - №569.

[2] Divya Kumar. The Impacts of Test Automation on Software's Cost, Quality and Time to Market / Divya Kumar, Krishn Kumar Mishra. // Procedia Computer Science. - 2016. - №79. - C. 8-15. 
[3] Rudolf Ramler. Economic perspectives in test automation: balancing automated and manual testing with opportunity cost / Rudolf Ramler, Klaus Wolfmaier. // Proceedings of the 2006 International Workshop on Automation of Software Test. 2006. - C. 85-91.

[4] Glenford J. Myers. The Art of Software Testing / Glenford J. Myers, Corey Sandler, Tom Badgett., 2011. - (John Wiley \& Sons).

[5] A Antonova, B Shanovskiy, Research and analysis of application of automated testing in web applications.// Automation of technological and business processes, 10 (1), 2018 - C. 55-57.

[6] E M Abdul Rauf. Software Test Automation: An Algorithm for Solving System Management Automation Problems / E M Abdul Rauf, E Madhusudhana Reddy. // Procedia Computer Science. - 2015. - №46. - C. 949-956.

[7] Norbert Oster. Automatic Test Data Generation by Multi-objective Optimisation / Norbert Oster, Francesca Saglietti. // SAFECOMP. - 2006. - №4166. - C. 426-438.

[8] Jalote Pankaj. An Integrated Approach to Software Engineering / Jalote Pankaj., 2012. - (Springer Science \& Business Media).

[9] Alan Page. How We Test Software at Microsoft / Alan Page, Ken Johnston, Bj Rollison., 2008. - 364 c. - (Microsoft Press).

[10] Antonia Bertolino. Software Testing Research: Achievements, Challenges, Dreams / Antonia Bertolino. // Future of Software Engineering. - 2007. - C. 85-103.

[11] Rex Black. Critical Testing Processes: Plan, Prepare, Perform, Perfect / Rex Black., 2003. - 608 c. - (Addison-Wesley Professional).

\section{References}

[1] H. Liangliang, Z. Jinsheng, M. Xiaoyu, "Development Trend of Software Process Model," IOP Conference Series: Materials Science and Engineering, no. 569, 2019.

[2] Divya Kumar, Krishn Kumar Mishra, "The Impacts of Test Automation on Software's Cost, Quality and Time to Market," Procedia Computer Science, no.79, pp C. 8-15, 2016.

[3] Rudolf Ramler, Klaus Wolfmaier, "Economic perspectives in test automation: balancing automated and manual testing with opportunity cost," Proc. of the 2006 International Workshop on Automation of Software Test, 2006, pp. 85-91.

[4] Glenford J. Myers, Corey Sandler, Tom Badgett, “The Art of Software Testing," John Wiley \& Sons, 2011.

[5] A. Antonova, B. Shanovskiy, "Research and analysis of application of automated testing in web applications," Automation of technological and business processes, 10 (1), pp. 55-57, 2018.

[6] E. M. Abdul Rauf, E. Madhusudhana Reddy, "Software Test Automation: An Algorithm for Solving System Management Automation Problems," Procedia Computer Science, no. 46, pp. 949-956, 2015.

[7] Norbert Oster, Francesca Saglietti, “Automatic Test Data Generation by Multi-objective Optimisation,” SAFECOMP,. No. 4166, pp. 426-438, 2006.

[8] Jalote Pankaj, “An Integrated Approach to Software Engineering,” Springer Science \& Business Media, 2012.

[9] Alan Page, Ken Johnston, Bj Rollison, "How We Test Software at Microsoft," Microsoft Press, 2008,364 p.

[10] Antonia Bertolino, "Software Testing Research: Achievements, Challenges, Dreams," Future of Software Engineering, pp. 85-103, 2007.

[11] Rex Black, "Critical Testing Processes: Plan, Prepare, Perform, Perfect,” Addison-Wesley Professional, 2003,608 p. 